\title{
Validated HPTLC Method to Estimate Silymarin in Marketed Herbal Formulation
}

\author{
Sharada L Deore, Hrutuja P Tidke, Somshekhar S Khadabadi, Bhushan A Baviskar, Anajli A Kide, Bhavna P Shende \\ Government College of Pharmacy, Amravati, Maharashtra, INDIA.
}

\begin{abstract}
Objectives: The objective of present research work is to develop simple, rapid and accurate high performance thin layer chromatographic method for quantitative estimation of silymarin in marketed hepatoprotective formulation. Methods: The separation was performed on silica gel $60 \mathrm{~F}_{254}$ precoated TLC aluminum plates and toluene: ethyl acetate: formic acid: methanol as mobile phase. Determination and quantitation were performed by densitometric scanning at $288 \mathrm{~nm}$. Validation of method is carried out as per International Conference of Harmonization $(\mathrm{ICH})$ guidelines. Results: Accuracy, precision and recovery were all within the required limits. Conclusion: In conclusion, the developed HPTLC method is precise and accurate for implementation in routine quality control. The selected
\end{abstract}

marketed hepatoprotective formulation contains the sufficient amount of the active ingredient which is required for its therapeutic efficiency.

Key words: Silymarin, Hepatoprotective formulation, HPTLC, ICH, Precision.

\section{Correspondence}

Sharada L Deore

Govt. College of Pharmacy, Amravati-444 604, Maharashtra, INDIA

Email: sharudeore_2@yahoo.com

DOI: 10.5530/ijpi.2021.1.10

\section{INTRODUCTION}

Silymarin (Figure 1), is 3, 5, 7-trihydroxy-2-[3-(4-hydroxy-3-methoxy phenyl)-2-(hydroxy-methyl)-1, 4-bezodioxan-6-yl]-4-chromanone. ${ }^{1}$ Silymarin is a hepatoprotective flavonoid drug available as bio marker in Silybum marianum, family (Asteraceae)..$^{2}$ It is commonly known as Marian thistle or Our lady's thistle or milk thistle or wild artichoke. ${ }^{3}$ It is significant therapeutic compound in many upcoming allopathic and neutraceutical formulations. Silymarin is a mixture of flavonolignans like silibinin, silicristin and silidianin. Silibinin is the major active component found to be responsible for antioxidant and hepatoprotive properties. ${ }^{1,2}$ It has been used in various liver disorders, as well as to prevent hepatotoxicity associated with poisoning. ${ }^{4}$ Different analytical methods that have been reported ${ }^{5-9}$ for estimation of Silymarin. The present research work aims to develop a simple, accurate, sensitive and reproducible method for analysis of silymarin by high performance thin layer chromatographic (HPTLC).

\section{MATERIALS AND METHODS}

\section{Materials}

Chemicals: The organic solvents and chemicals of analytical grade were procured from S.D Fine Chemicals Pvt. Ltd., Mumbai, India. Standard silymarin was obtained from the Yucca Enterprises, Mumbai. A marketed formulation [H1] tablet manufactured by Micro Labs Limited was purchased from Local market. The stationary phase used was 0.2 mm thick silica gel $60 \mathrm{~F}_{254}$ precoated TLC plates obtained from E. Merck Ltd., Mumbai, India.

Instrumentation: CAMAG HPTLC system (Anchrom Switzerland) including Camag - Linomat 5 -Sample applicator, Camag Twin Trough chamber with stainless steel lids for chromatographic development, Camag TLC Scanner 3 equipped with WINCATS software for scanning and documentation, Camag UV cabinet. Ultrasonicator. Analytical Balance of Shimadzu and UV Spectrophotometer: 240 IPC Shimadzu and Software UV PC V 3.9.

\section{Methods}

Preparation of Standard solution: Stock solution of silymarin $(1000 \mu \mathrm{g} /$ $\mathrm{ml}$ ) was prepared by dissolving $10 \mathrm{mg}$ of accurately weighed standard in $10 \mathrm{ml}$ of methanol. From this stock solution, $100 \mu \mathrm{g} / \mathrm{ml}$ solution was prepared by transferring $1 \mathrm{ml}$ stock solution to $10 \mathrm{ml}$ volumetric flask then volume adjusted with methanol.

Preparation of Sample solution: $597.5 \mathrm{mg}$ of powdered tablet as per equivalent weight dissolved in methanol and volume made up in the 50 $\mathrm{ml}$ volumetric flask to give $1000 \mu \mathrm{g} / \mathrm{ml}$ of stock solution of powdered tablet. Then $5 \mathrm{ml}$ of stock solution diluted with $50 \mathrm{ml}$ methanol in volumetric flask to give $100 \mu \mathrm{g} / \mathrm{ml}$ sample solution.

Optimization of Mobile phase: The standard stock solution containing $100 \mu \mathrm{g} / \mathrm{ml}$ of silymarin was spotted on to TLC plate and developed in different solvent systems. ${ }^{10}$ Many preliminary trials were carried out for selection of mobile phase. Mobile phase composition was optimized to provide precise, specific and reproducible results for the estimation of silymarin.

Chromatographic conditions: Based on solubility, methanol was used as a common solvent for the preparation of standard and sample solution and also for the mobile phase preparation and chromatographic conditioning. Optimised chromatographic conditions are: Wavelength$288 \mathrm{~nm}$, stationary phase-precoated silica gel $60 \mathrm{~F}_{254}$ and mobile phasetoluene: ethyl acetate: methanol: formic acid (10: 10: 4 drop: 2 drop). Chromatogram up to $80 \mathrm{~mm}$ distance is developed by ascending method in $30 \mathrm{~min}$ pre-saturated Camag glass twin-trough chamber at $25^{\circ} \mathrm{C}$ temperature. Developed plates scanned with a Camag TLC Scanner 3 having win CATS software at $288 \mathrm{~nm}$ after drying the plates.

Calibration Curve of Silymarin: The stock solution of silymarin (100 $\mu \mathrm{g} / \mathrm{ml}$ ) was prepared in methanol. Different volumes of stock solutions $2,4,6,8,10$ and $20 \mu \mathrm{l}$ [S1-S6] were spotted on TLC plate to obtain concentrations of $200 \mathrm{ng}, 400 \mathrm{ng}, 600 \mathrm{ng}, 800 \mathrm{ng}$, 1000ng and 2000ng per spot respectively. $\mathrm{H} 1$ and $\mathrm{H} 2$ spots of marketed tablet formulations were 
<smiles>COc1cc(C2Oc3cc(C4Oc5cccc(O)c5C(=O)C4(C)C)ccc3OC2CO)ccc1O</smiles>

Figure 1: Structure of silymarin.

applied. The data of peak area versus drug concentration were treated by linear least square regression analysis.

Method validation: The optimized HPTLC method was validated with respect to following parameters in accordance with ICH Q2 (R1) guidelines. ${ }^{11}$

Linearity Studies: The linearity helps to determine a range of concentration in which results are directly proportional to the concentration of marker compound in the extract/s. Peak area v/s concentration graph of standard marker compound plotted to get correlation coefficient $\left(\mathrm{r}^{2}\right)$ and equation of the line. The standard silymarin $(100 \mu \mathrm{g} / \mathrm{ml})$ solution was applied over the plate in duplicates; the curve was prepared in the concentration range of 200 to $2000 \mathrm{ng}$. The $\mathrm{Y}$ intercepts, correlation coefficients and residual standard deviations of the responses were calculated for the determination of linearity range. Calibration curve was obtained by plotting peak vs. concentration of analyte-marker compound.

Accuracy Studies: The accuracy helps to determine the degree to which the result of a marker compound estimation conforms to accept correct or a reference value. Accuracy of the method was studied by means of recovery studies. Recovery studies carried out in triplicates by adding known amount of standard to three concentration levels viz. $80 \%, 100 \%, 120 \%$. The known quantities of marker compounds are spiked in the sample spots by means of over spotting and the amount recovered is calculated by using regression equation which was obtained from calibration curves.

Precision Studies: The precision expresses the closeness of agreement (degree of scatter) between a series of results obtained under same experimental conditions from multiple sampling of the same homogeneous sample. Repeatability, intermediate precision and reproducibility are considered as three levels of precision. Precision studies were carried out by using the tablet solution. Six spots of $4 \mu \mathrm{l}$ of same tablet solution were applied on the plate and the plate was scanned at $288 \mathrm{~nm}$ after development. The amount of silymarin present per track was calculated by using regression equations of line. The relative standard deviation within responses was calculated to determine the precision of the method.

Limit of Detection (LOD) and Limit of Quantitation (LOQ) Studies: In order to estimate the limit of detection (LOD) and limit of quantification (LOQ), blank methanol was spotted six times in a similar way to that of the calibration curve and the signal-to-noise ratio was determined. The calculation was based on the standard deviation (SD) of the response and the slope (S) of the calibration curve. The LOD was considered as 3:1(SD/S) and LOQ as 10:1(SD/S)

Robustness Studies: Robustness is the capacity of a method to remain unaffected by small deliberate variations in method parameters. Method parameters like mobile phase proportion, $\mathrm{pH}$, analyst, ionic strength, temperature and or any other parameter affecting results of the method can be used to evaluate robustness of a method.

\section{RESULTS}

The spectral scan of silymarin was obtained and it exhibited $\lambda_{\max }$ at 288 $\mathrm{nm}$ (Figure 2), which is utilized for further quantitative estimation. Well-defined sharp peak with better resolution obtained in HPTLC chromatogram at $0.45 \pm 0.05 \mathrm{R}_{f}$ value. (Figure 3 and 4 )

The linearity range for silymarin is found $200-2000 \mathrm{ng} / \mathrm{spot}$ as shown in Figure 5. The linearity regression co-efficient $\left(\mathrm{r}^{2}\right)$ value, limits of detection (LOD) and quantification (LOQ) are summarised in Table 1. Results of accuracy are given in Table 2. Results of precision and reproducibility of the developed HPTLC method are summarised in Table 3. The contents of silymarin quantified in marketed formulation using HPTLC densitometric methods are found to be as per label claim.

\section{DISCUSSION}

Herbal dietary supplements use is steadily increasing and Silybum marianum based dietary supplements are among best selling supplements all over the world to treat liver diseases like alcoholic liver disease, non-alcoholic fatty liver disease, viral hepatitis and or drug-induced liver disease. Silymarin, a mixture of flavonolignans is found to have antioxidant, anti-inflammatory, immunomodulating and liver regenerating properties. Safety and efficacy of Herbal dietary supplements is always questionable due to undefined rules unlike drugs and varying chemical composition in reference to potentially bioactive fraction. Therefore, the aim of the present study was to ascertain the label claimed composition of marketed hepatoprotective formulation.

Table 1: Linear studies of silymarin.

\begin{tabular}{cc}
\hline Parameters & Silymarin \\
\hline Selectivity & Selective \\
Specificity & Specific \\
Linearity Range (ng/spot) & $200-2000 \mathrm{ng}$ \\
Equation & $\mathrm{Y}=3.006 \mathrm{x}+462.5$ \\
Correlation coefficient (r2) & 0.997 \\
Slope & 3.006 \\
Intercept & 462.5 \\
LOD (ng/spot) & 2.13 \\
LOQ (ng/spot) & 6.46 \\
Percentage recovery & 99.74 \\
Repeatability (\%RSD, $n=6)$ & 0.234 \\
Robustness & Robust
\end{tabular}

Table 2: Recovery studies of Silymarin.

\begin{tabular}{ccccc}
\hline $\begin{array}{c}\text { Sample } \\
\text { Content } \\
\text { (ng/spot) }\end{array}$ & $\begin{array}{c}\text { Spiked } \\
\text { amount } \\
\text { (ng/spot) }\end{array}$ & $\begin{array}{c}\text { Total amount } \\
\text { (ng/spot) }\end{array}$ & $\begin{array}{c}\text { Amount } \\
\text { Recovered } \\
\text { (ng/spot) }\end{array}$ & $\begin{array}{c}\% \\
\text { Recovery }\end{array}$ \\
\hline $1003.74 \mathrm{ng}$ & $50 \mathrm{ng}$ & 1053.74 & 1051.54 & 98.92 \\
$1003.74 \mathrm{ng}$ & $50 \mathrm{ng}$ & 1053.74 & 1052.23 & 99.25 \\
$1003.74 \mathrm{ng}$ & $100 \mathrm{ng}$ & 1103.74 & 1104.56 & 100.40 \\
$1003.74 \mathrm{ng}$ & $100 \mathrm{ng}$ & 1103.74 & 1104.82 & 100.72 \\
$1003.74 \mathrm{ng}$ & $100 \mathrm{ng}$ & 1103.74 & 1102.24 & 99.40 \\
$\begin{array}{c}\text { Average } \\
\text { recovery (\%) }\end{array}$ & & & 99.74 & \\
\hline
\end{tabular}


Table 3: Intra and inter day precision of HPTLC method of Silymarin.

\begin{tabular}{ccccc}
\hline $\begin{array}{c}\text { Amount ng/ } \\
\text { spot }\end{array}$ & \multicolumn{2}{l}{ Intra day precision } & \multicolumn{2}{l}{ Inter day precision } \\
\hline & SD & \%CV & SD & $\% \mathrm{CV}$ \\
200 & 21.57 & 0.91 & 20.3 & 0.63 \\
400 & 27.23 & 1.42 & 27.23 & 1.06 \\
600 & 18.82 & 0.82 & 36.12 & 1.07 \\
800 & 25.01 & 0.72 & 15.87 & 0.74 \\
1000 & 30.02 & 1.33 & 23.69 & 1.02 \\
2000 & 43.03 & 1.32 & 28.02 & 0.91 \\
\hline
\end{tabular}

Table 4: The Parameters used for the robustness/ruggedness.

\begin{tabular}{|c|c|c|c|c|}
\hline $\begin{array}{l}\text { Sr. } \\
\text { No. }\end{array}$ & Parameter & $\begin{array}{c}\text { Initial } \\
\text { Condition }\end{array}$ & $\begin{array}{l}\text { Changed } \\
\text { Condition }\end{array}$ & Effect \\
\hline 1 & $\begin{array}{l}\text { Mobile } \\
\text { Phase }\end{array}$ & $\begin{array}{c}\text { Toluene: } \\
\text { Ethyl Acetate: } \\
\text { Formic Acid: } \\
\text { Methanol (10: } \\
\text { 10: } 4 \text { drops: } 2 \\
\text { drops) }\end{array}$ & $\begin{array}{c}\text { Toluene: Ethyl } \\
\text { Acetate: Formic } \\
\text { Acid: Methanol } \\
\text { (8: 12: } 4 \text { drops: } 2 \\
\text { drops) }\end{array}$ & $\begin{array}{l}\mathrm{Rf} \text { increased but no } \\
\text { effect on resolution }\end{array}$ \\
\hline 2 & Temperature & $25^{\circ} \mathrm{C}$ & $30^{\circ} \mathrm{C}$ & $\begin{array}{l}\text { Number of bands } \\
\text { increased. Rf } \\
\text { of components } \\
\text { slightly increased }\end{array}$ \\
\hline 3 & $\begin{array}{c}\text { Tank } \\
\text { Saturation } \\
\text { Time }\end{array}$ & $15 \mathrm{~min}$ & $20 \mathrm{~min}$ & $\begin{array}{l}\text { Plate take max time } \\
\text { for development }\end{array}$ \\
\hline 4 & $\begin{array}{l}\text { Extracting } \\
\text { Solvent }\end{array}$ & Methanol & Ethanol & No Effect \\
\hline 5 & Analyst & User 1 & User 2 & No Effect \\
\hline
\end{tabular}

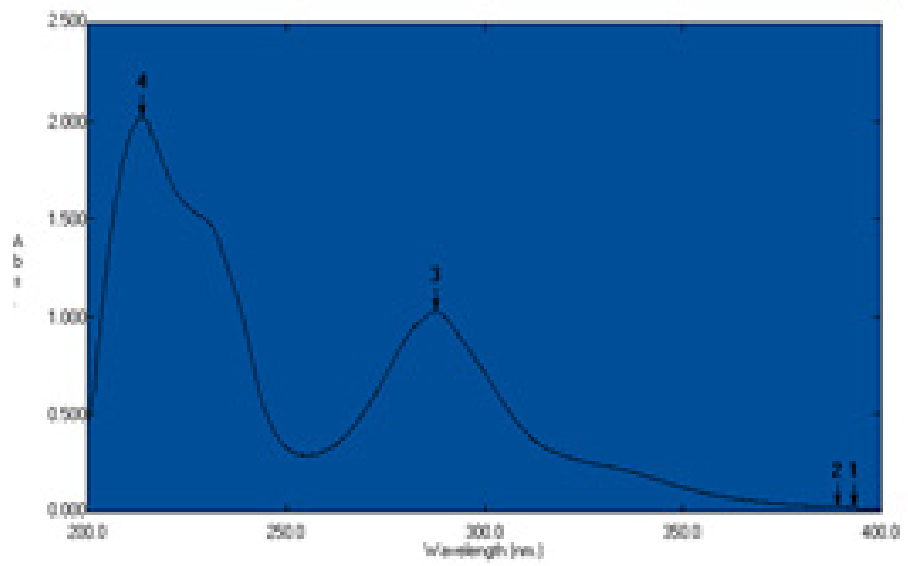

Figure 2: Spectral scan of Silymarin Standard.

High-performance thin-layer chromatography (HPTLC) is an important technique for the phytochemical composition screening, fingerprinting and chemical marker compound estimation in analysis of herbal drugs and derived products. HPTLC is most preferred quantitative estimation method for phytochemicals in polyherbal formulations due to its simple and accurate reproducibility.

The spectral scan of silymarin was obtained and it exhibited $\lambda_{\max }$ at 288 $\mathrm{nm}$ (Figure 2), which is utilized for further quantitative estimation to get selective and sharp peak responses. The experimental conditions for HPTLC such as stationary phase, mobile phase composition and detection wavelength are optimized to provide accurate, reproducible and precise results for estimation of silymarin. Initially stock solution containing $100 \mu \mathrm{g} / \mathrm{ml}$ of silymarin was spotted on TLC plate and it was developed in different solvent systems. Good resolution and sharp peaks with minimum tailing was obtained using mobile phase consisting of toluene: ethyl acetate: formic acid: methanol in the ratio of 10: 10: 4 drop: 2 drop. Silymarin gave better, sharp and well-defined peak resolution at $0.45 \pm 0.05 \mathrm{R}_{f}$ value. (Figure 3)

Silymarin standard was quantified accurately using silica gel $\mathrm{F}_{254}$ HPTLC pre-coated plates with mobile phase toluene: ethyl acetate: formic acid: methanol in the ratio of 10: 10: 4 drop: 2 drop, the $\mathrm{R}_{f}$ value was about 0.45. [Figure 4] The chromatographs of silymarin (S1-S6) and herbal formulation $(\mathrm{H} 1-\mathrm{H} 2)$ are shown in Figure 3 . The $\mathrm{R}_{f}$ value of silymarin matched with the $\mathrm{R}_{f}$ value of herbal formulation was about 0.45 shown in peak in Figure 3.

The HPTLC densitometric method was validated in terms of precision, repeatability, accuracy, LOD and LOQ. The linearity range for silymarin was 200-2000 ng/spot (Table 1) with correlation coefficient, intercept and the slope 0.997 (sdv 0.05), 3.006 and 462.5 respectively ( $\mathrm{Y}=3.006 \mathrm{X}$ $+462.5)$

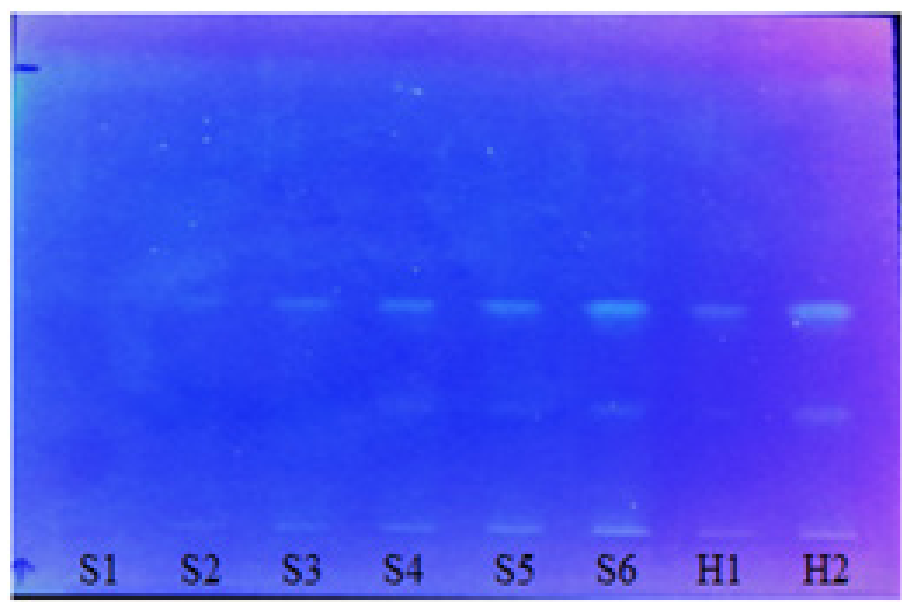

Figure 3: Chromatogram of Standard Silymarin [S1-200 ng, S2-400 ng, S3-600 ng, S4-800 ng, S5-1000ng and S6-2000ng H1 \& H2- Marketed formulation]

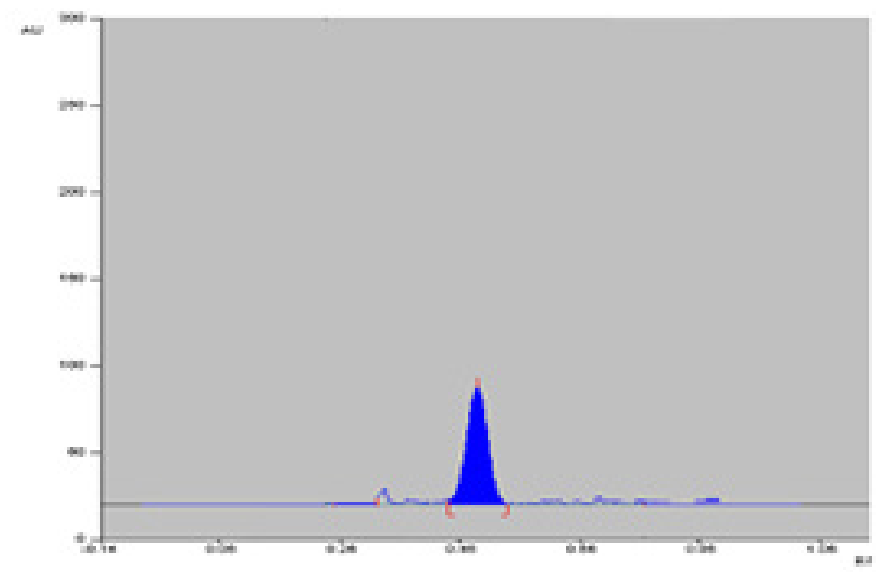

Figure 4: Densitometric chromatogram of Silymarin [200ng/spot]. 


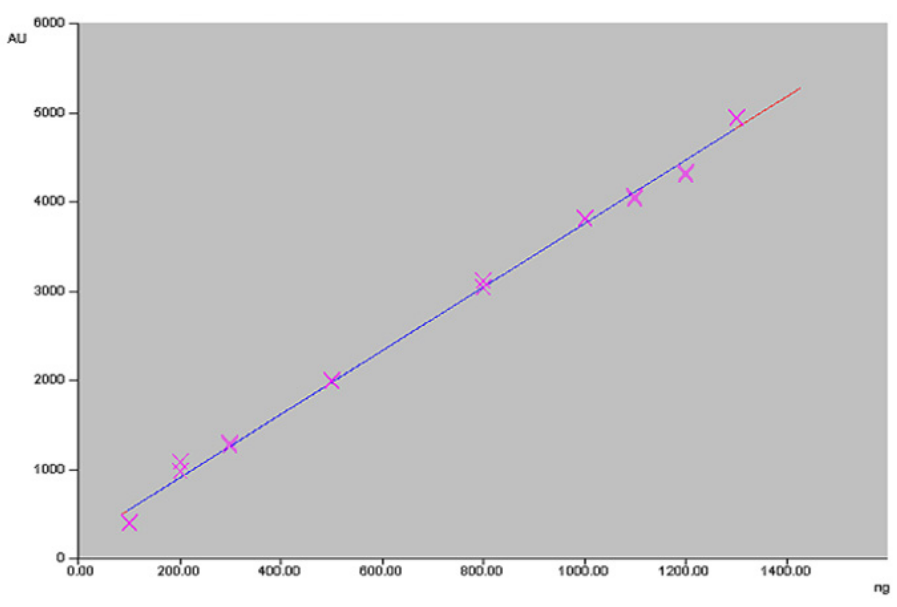

Figure 5: Calibration Curve of Silymarin.

Linearity of the developed method was studied by plotting calibration curve [Figure 5] of silymarin using different concentration levels such as $2,4,6,8,10$ and $20 \mu 1$ respectively. The linearity regression co-efficient $\left(\mathrm{r}^{2}\right)$ value was found 0.997 for silymarin as shown in Table 1. Results of accuracy are given in Table 2 .

The percentage recovery was in the range of $98.92-100.72 \%$. Low values of $\% \mathrm{CV}(<2 \%)$ in inter-day and intra-day variation ${ }^{11}$ indicates an excellent precision and reproducibility of the developed HPTLC method (Table 3).

The limits of detection (LOD) and quantification (LOQ) were 2.13 and $6.46 \mathrm{ng}$, respectively which indicates the adequate sensitivity of the method (Table 1).

The robustness and ruggedness parameters such as mobile phase composition, temperature, tank saturation time, extraction solvents and analyst changes are generally considered for these studies. This change and their respective effect are indicated in Table 4.The standard deviations of peak areas were calculated for each parameter and \%RSD was found to be less than 3\%. Small deliberate changes made in developed HPTLC method lead to low values of \%RSD indicated the robustness of the method. Small but purposeful variations in the experimental parameters showed that developed HPTLC method remained unchanged which indicates suitability and reliability of the developed rugged method for routine analysis. The contents of silymarin quantified using HPTLC densitometric methods were found to be as per label claim.

\section{CONCLUSION}

From the results, it is concluded that the method developed is precise and accurate. The selected marketed product contains the sufficient amount of the active ingredient which is required for its therapeutic efficiency. Standardization itself is the future of phytochemical containing formulations/drugs which ensures the quality of the natural products and also having the desired therapeutic effect. No herbal/ natural formulation will be the placeboes if such pit falling factors are identified and controlled.

\section{ACKNOWLEDGEMENT}

Authors are thankful to HPTLC Facility centre of Institute of Pharmaceutical Education \& Research (IPER), Wardha, Maharashtra.

\section{CONFLICT OF INTEREST}

The authors declare no potential conflicts of interest with respect to the research, authorship and/or publication of this article.

\section{ABBREVIATIONS}

HPTLC: high performance thin layer chromatography; TLC: Thin Layer Chromatography; LOD: limits of detection; LOQ: Limit of quantification; $\mathbf{R}_{f}$ : Retention factor; CV: coefficient of variation; RSD: relative standard deviation; SD: Standard Deviation; S: slope (S).

\section{REFERENCES}

1. Firke SD, Patel N, Surana SJ, Bari SB. Method Development and Validation of silymarin in bulk and pharmaceutical formulation by UV - spectrophotometric area under curve method (AUC). Anal Chem Ind J. 2015;15(3):100-4

2. Gul S, Khanum K, Mujtaba N. New validated method for analysis of silymarin in polyherbal formulation (aqueous extract, oral liquid and solid dosage form). Cl. 2015;1(3):103-6.

3. Patil SG, Jadhav VM, Kadam VJ. Method development and validation for simulteneous estimation of gallic acid and piperine in herbal extract and polyherbal formulation by HPTLC. WJPS. 2014;4(1):738-48.

4. Fraschini F, Demartini G, Esposti D. Pharmacology of Silymarin. Clin Drug Invest. 2002;22(1):51-65.

5. Parveen R, Ahmad S, Baboota S, Ali J, Ahuja A. Stability indicating HPTLC method for quantitative estimation of silybin in bulk drug and pharmaceutical dosage form. Biomed Chromatogr. 2009;24(6):639-47.

6. Upendra S, Baldi A. Simultaneous Estimation of Quercetin and Silymarin: Method Development and Validation. IJPBA. 2013;4(3):527-31.

7. Korany MA, Haggag RS, Ragab MA, Elmallah OA. A validated stability - indicating HPLC method for simultaneous determination of silymarin and curcumin in various dosage forms. Arab J of Pharm. 2013;10:S1711-25.

8. Chaudhari S, Mannanand A, Daswadkar S. Development and Validation of UV Spectrophotometric Method for Simulteneous Estimation of Acyclovir and Silymarin in Niosome Formulation. Der Pharmacia Letter. 2016;8(5):128-33.

9. Dube D, Vyas SP. Simulteneous Spectrophotometric Estimation of Lamivudine and Silymarin in mixture. Int J Pharm Pharm Sci. 2009;1(2):107-11.

10. Wagner S. Bladt; Plant Drug Analysis. Second edition; Springer. 2009;352-4.

11. International Conference on Harmonization of Technical Requirements for Registration of Pharmaceutical for Human use ICH Guidelines. Validation of analytical procedures text and methodology Q2B (R1). 2005. 